DOI: https://doi.org/10.47405/mjssh.v5i11.552

\begin{tabular}{|c|c|}
\hline 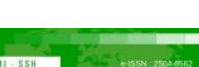 & Malaysian Journal of Social Sciences and Humanities (MJSSH) \\
\hline Malaysian Journal of & Volume 5, Issue 11, November 2020 \\
\hline (Mu-ssH) & e-ISSN : 2504-8562 \\
\hline & $\begin{array}{l}\text { Journal home page: } \\
\text { www.msocialsciences.com }\end{array}$ \\
\hline
\end{tabular}

\title{
Menyingkap Polemik Peralihan Kuasa Secara Luar Biasa Mengikut Perspektif Demokrasi Berparlimen
}

\author{
Mohd Sohaimi Esa1, Mohd Azri Ibrahim ${ }^{1}$, Abang Mohd. Razif Abang Muis' \& Romzi Ationg1 \\ 1Pusat Penataran Ilmu dan Bahasa dan Bahasa, Universiti Malaysia Sabah (UMS) \\ Correspondence: Mohd Sohaimi Esa(msohaimi@ums.edu.my)
}

\begin{abstract}
Abstrak
Polemik peralihan kuasa merupakan salah satu dinamika dalam perdebatan politik. Ini termasuklah polemik peralihan kuasa luar biasa yang berlaku di beberapa buah negara di Asia Tenggara seperti Indonesia, Filipina dan Thailand. Namun, di Malaysia, hal ini tidak pernah berlaku bila mana demokrasi berperlembagaan yang diamalkan sejak merdeka menjadi teras kepada pemerintahan dan pentadbirannya. Pasca Pilihan raya Umum ke-14 (PRU-14), bagaimanapun, mengubah fakta tersebut apabila isu peralihan kuasa terus mendominasi suasana politik di Malaysia, khususnya peralihan kuasa melibatkan pucuk kepimpinan negara, yakni jawatan Perdana Menteri. Berdasarkan penelitian dokumen sekunder dari pelbagai sumber seperti akhbar dan kenyataan politik di kalangan ahli politik, kertas kerja ini membincangkan tentang sejauh manakah isu peralihan kuasa jawatan Perdana Menteri itu dapat dianggap luar biasa dalam sistem demokrasi berparlimen. Artikel ini turut membincangkan tentang penerimaan rakyat Malaysia keseluruhannya idea mengangkat kepimpinan dari tanah Borneo sebagai Perdana Menteri serta kaedah sewajarnya bagi mengatasi kemelut peralihan kuasa. Diharap agar dapatan artikel ini menyumbang kepada pelestarian keharmonian berpolitik di negara Malaysia
\end{abstract}

Kata kunci: polemik peralihan kuasa, peralihan kuasa luar biasa, Malaysia, demokrasi, dinamika politik

\section{Unveiling the Abnormal Power Transition Polemic through the Perspective of Parliamentary Democracy}

\begin{abstract}
The transfer of power polemics is one of the dynamics in political discourse. This includes the extraordinary power transition polemics in Southeast Asian countries such as Indonesia, Philippines and Thailand. In Malaysia, however, such phenomenon was not the case within the framework of constitutional democracy practiced since independence as it has been the core principles in public governance and administration. After the 14th General Election (GE-14), however, the politics of Malaysia changed when the issue of power transfer dominates the political talks, particularly the power transition involving the top leadership of the country, the post of a Prime Minister. Based on examination of secondary documents from various sources such as newspapers and press statements by the politicians, this paper discusses the extent to which the issue of power transfer of the Prime Minister can be considered extraordinary in the parliamentary democracy system. This paper also discusses the acceptance of Malaysians on the idea of elevating leadership from Borneo as a Prime Minister of Malaysia as well as appropriate methods to overcome the present power transition crisis. It is hoped that the findings of this paper contribute to the preservation of political harmony in Malaysia.
\end{abstract}


Keywords: power transition polemics, extraordinary power transition, Malaysia, democracy, political dynamics

\section{Pengenalan}

Polemik peralihan kuasa merupakan salah satu dinamika dalam disiplin politik yang menarik untuk dibincangkan dan diperdebatkan, terutamanya apabila dilihat dalam konteks amalan sistem demokrasi berperlembagaan. Jika diperkatakan polemik peralihan kuasa luar biasa ini sebenarnya bukanlah sesuatu yang baharu, malah berlaku juga di beberapa buah negara Asia Tenggara seperti Indonesia, Filipina dan Thailand. Di Malaysia, keadaan sedemikian tidak pernah berlaku bila mana demokrasi berperlembagaan yang diamalkan sejak merdeka menjadi teras kepada pemerintahan dan pentadbirannya. Hal ini menjadikannya begitu unik dengan raja menjadi penaung kepada rakyat, sementara rakyat menentukan kuasa pentadbiran kerajaan. Pilihan raya menjamin pelestarian sistem demokrasi di negara ini yang terdiri daripada masyarakat pelbagai kaum dan agama. Dari segi sejarah, peralihan kuasa selama ini telah berjalan dalam keadaan normal dan biasanya tiada berlakunya konflik yang dianggap abnormal. Hal ini berlaku kerana sepanjang tempoh 60 tahun negara berkerajaan hanya Parti Perikatan, dan kemudiannya dikenali sebagai Barisan Nasional $(\mathrm{BN})$ yang menerajui pentadbiran negara yang memungkinkan proses peralihan kuasa berjalan dengan baik tanpa sebarang konflik ketara.

Walau bagaimanapun, kemenangan Pakatan Harapan (PH) dalam Pilihan Raya Umum ke-14 telah menyaksikan perubahan ketara dalam landskap politik di Malaysia. dalam erti kata yang lain perubahan ini berlaku berikutan tumbangnya kerajaan Barisan Nasional dan gabungan parti pembangkang, PH mengambil alih kuasa pentadbiran negara. Perubahan kerajaan ini dianggap sebagai suatu kejutan dan tanpa disangka oleh rakyat, termasuk para penganalisis politik tempatan dan luar negara (Muhamad Nadzri Mohamed Noor \& Nidzam Sulaiman, 2018; Chan, 2018; Welsh, 2018). Dalam pada itu, para penganalisis politik menganggap perubahan kuasa ini menunjukkan kematangan rakyat dalam berpolitik dan amalan sistem demokrasi di Malaysia (Moniruzzaman \& Farzana, 2018; Muhammad Nadzri Mohamed Noor, 2018). Hal ini dibuktikan apabila peralihan kuasa berlaku dalam keadaan aman dan harmoni. Sekalipun demikian, perkembangan ini membawa implikasi besar apabila landskap politik Malaysia menuju ke-arah sistem dua parti yang didapati semakin subur. Lebih istimewa lagi apabila gabungan parti-parti politik masih kekal dengan identiti sistem kepartian mereka. Malah gabungan kepartian ini didapati merentasi kaum dan agama, serta diintegrasikan dengan wilayah Semenanjung, Sabah dan Sarawak. Persoalannya, sejauh manakah perubahan tersebut telah membawa kejutan dalam polemik peralihan kuasa di Malaysia?.

Bagi menjawab persoalan ini maka adalah perlu penilaian perkembangan politik negara sejak berakhirnya Pilihan Raya Umum ke-14 yang diadakan pada tahun 2018. Dalam hal ini, adalah wajar ditegaskan bahawa berikutan kekalahan BN pada tahun tersebut (2018), isu peralihan kuasa selepas pilihan raya terus mendominasi suasana politik di Malaysia. Perkembangan ini juga memperlihatkan trend baru yang didominasi oleh isu peralihan kuasa melibatkan pucuk kepimpinan negara, yakni jawatan Perdana Menteri. Perdana Menteri sebagai ketua kerajaan dianggap penting kerana menjadi tunjang kepada amalan sistem demokrasi berparlimen di Malaysia (Shad Saleem Faruqi, 2020). Jawatan ini masih menjadi 'kerusi panas' yang dianggap masih belum mempunyai jalan penyelesaiannya. Malahan menarik untuk dibincangkan dan diperdebatkan apabila watak jawatan ini tidak lagi bertumpu kepada personaliti politik utama negara iaitu Tun Dr Mahathir Mohamed dan Datuk Seri Anwar Ibrahim, malahan muncul beberapa watak lain antaranya termasuklah Tan Seri Muhyiddin Mohd Yassin dan Datuk Sri Shafii Afdhal. Natijahnya, pergolakan tersebut ada kalanya mengganggu sistem pentadbiran dan pemerintahan negara. Bahkan secara sedar atau tidak keadaan ini menyebabkan rakyat dan pelabur semakin gelisah dengan perkembangan tersebut. Keadaan ini ditambah lagi dengan isu pandemik Covid-19 yang turut menyulami suasana suram politik Malaysia. Persoalannya, sejauh manakah isu peralihan kuasa jawatan Perdana Menteri itu dapat dianggap luar biasa dalam sistem demokrasi berparlimen? Apakah kepimpinan dari Sabah dan Sarawak dapat 
diterima oleh rakyat Malaysia secara keseluruhannya, khususnya rakyat negara ini yang berada di Semenanjung Malaysia dan Sarawak? Seterusnya, bagaimanakah jalan terbaik untuk menyelesaikan isu ini agar tidak berpanjangan? Justeru itu, persoalan tersebut akan dibincangkan secara akademik bagi merungkaikan jawapannya. Kaedah penyelidikan primer dan sekunder sebagaimana yang dicadangkan oleh Ahmad Tarmizi, Romzi \& Nurul (2017) diguna pakai sebagai asas perbincangan bagi isu ini khasnya daripada dokumentasi perlembagaan Malaysia, laporan media, laporan kajian Pilihan Raya Umum (PRU) 2018 dan pemerhatian umum. Perbincangan artikel ini dipecahkan kepada tiga bahagian utama iaitu konsep demokrasi berparlimen dan proses peralihan kuasa secara normal, polemik peralihan kuasa luar biasa dan perbincangannya dalam dimensi Malaysia.

\section{Konsep Demokrasi Berparlimen dan Proses Peralihan Kuasa Normal}

Demokrasi merupakan istilah yang begitu popular dewasa ini, terutamanya pada era globalisasi atau dunia tanpa sempadan. Demokrasi sering menjadi sebutan, bualan dan perbincangan dalam masyarakat global, khususnya di Malaysia (Romzi, 2017). Demokrasi merupakan amalan dalam pemerintahan negara yang berteraskan kepada peruntukan perlembagaan dan undang-undang. Kematangan politik, gelombang perkembangan sumber maklumat siber, peningkatan taraf pendidikan dan pembangunan urban adalah antara penyebab utama kepada kebangkitan kesedaran serta penyertaan aktif semua lapisan masyarakat dalam aktiviti politik demokrasi. Laungan dan desakan agar kerajaan lebih bersifat demokratik dalam sesuatu hal menunjukkan rakyat semakin sedar tentang hak dan kepentingan mereka dalam sebuah negara yang mengamalkan sistem politik demokrasi. Oleh itu, sistem politik dan amalan demokrasi sentiasa terdedah kepada perbahasan dan mungkin juga konflik kepentingan berdasarkan individu atau pihak-pihak tertentu yang terlibat (Mohd Azri, Romzi, Mohd Sohaimi \& Madiyem, 2020).

Istilah demokrasi berasal dari dua perkataan Greek iaitu 'demos' yang bermaksud rakyat dan 'kratia' yang bermaksud pemerintahan (Ranney, 1993; Roskin, 2000). Oleh itu, demokrasi dapat dirumuskan sebagai pemerintahan yang diuruskan oleh rakyat dalam sesebuah negara. Ini jelas menunjukkan bahawa corak pemerintahan sebenarnya adalah atas kepentingan dan kehendak rakyat. Namun demikian, bentuk pemerintahan demokrasi secara langsung tidak digunakan oleh negara-negara lain iaitu selepas ia dipopularkan di negara Greek purba. Pemerintahan pada waktu itu terkenal sebagai pemerintah yang bercorak monarki. Raja-Raja telah memegang tampuk pemerintahan tanpa mempedulikan pendapat atau suara rakyat. Raja-Raja berkenaan menganggap diri mereka telah ditauliahkan oleh Tuhan untuk memerintah. Walau bagaimanapun keadaan berkenaan telah berubah akibat revolusi dan gerakan pembebasan di Amerika Syarikat (1750-an) dan penggulingan sistem beraja di Perancis (1850-an) apabila corak pemerintahan sesebuah negara telah diberikan nafas baru iaitu seruan ke-arah corak demokrasi dan sehingga kini kita dapati sejumlah besar negara mengamalkan pemerintahan yang bercorak demokrasi (Dunn, 1992; Ghazali, 2006).

Demokrasi kini merupakan corak pemerintahan secara tidak langsung iaitu pemerintahan berbentuk perwakilan atau demokrasi berparlimen seperti di Malaysia. Apabila kita membicarakan aspek yang berkaitan dengan perwakilan bagi pihak rakyat, secara tidak langsung ia ada kaitan dengan amalan pilihan raya. Pilihan raya merupakan suatu amalan yang sering digunakan oleh sesebuah negara yang mengamalkan pemerintahan yang bercorak demokrasi. Penglibatan rakyat dalam pilihan raya adalah sangat penting dan juga bermakna kepada calon-calon yang akan memegang tampuk pemerintahan. Ini kerana rakyat yang akan mengundi calon-calon yang bertanding dan kemenangan adalah berdasarkan kepada majoriti undi yang diperoleh dalam pilihan raya tersebut. Kemenangan ini merupakan bukti yang nyata bahawa mereka telah mendapat mandat atau sering juga dikenali sebagai legitimasi daripada rakyat untuk mewakili mereka dalam sebarang aktiviti pembuatan dasar negara dan juga memperjuangkan kepentingan rakyat keseluruhannya. Oleh itu demokrasi sangat berkait rapat dengan amalan pilihan raya dan pilihan raya pula sangat berkaitan rapat dengan proses pembentukan kerajaan yang akan memerintah.

Prinsip-prinsip asas sistem politik demokrasi menurut penyelidik dan pakar politik terdahulu seperti Roskin (2000) dan Ranney (1993) merupakan suatu hal yang wajar difahami secara lebih meluas dan 
mendalam. Roskin (2000) telah menggariskan beberapa prinsip yang perlu ada dalam sesebuah negara demokrasi iaitu kebertanggungjawaban kerajaan, persaingan politik, alternatif kuasa, perwakilan, keputusan yang berteraskan majoriti, memelihara hak minoriti, persamaan politik, perundingan politik dan kebebasan media. Manakala Ranney (1993) pula melihat demokrasi sebagai “... a form of government organized in accordance with the principles of popular sovereignty, political equality, popular consultation and majority rule" (m/s. 100-101). Berdasarkan kenyataan Ranney dan Roskin ini adalah jelas bahawa aspek demokrasi seharusnya dilihat dari sudut pandangan yang lebih luas dan mendalam kepada aspek-aspek seperti majoriti. Dalam hal ini sudah pasti ia merujuk kepada rakyat atau warganegara dalam sesebuah negara. Ranney (1993) turut menambah bahawa, “... when ultimate power is vested in one person, the government is a dictatatorship, when it is vested in a few person they constitute aruling elite and the government is what political scientists call an oligarchy or aristocracy; the only when it is vested in all the people is the government a democracy" (m/s. 101).

Diamond dan Plattner (1994) seterusnya telah membahaskan konsep demokrasi dalam konteks nasionalisme dan konflik etnik. Menurut mereka "the core of democracy is the principle of popular sovereignty" (m/s. 5). Ini adalah jelas menunjukkan bahawa nilai kedaulatan umum menjadi teras kepada sistem politik demokrasi dalam sesebuah negara. Oleh itu, proses utama dalam melaksanakan prinsip kedaulatan umum dalam sistem demokrasi ialah melalui pendekatan pilihan raya. Dalam hal ini, mereka telah mengutarakan satu pendekatan yang menarik untuk dibincangkan iaitu amalan demokrasi menuntut kepada tindakan rasional yang tinggi. Ini menunjukkan bahawa dalam sistem politik demokrasi, sesuatu tindakan dan keputusan yang diambil sangat memerlukan penilaian yang rasional oleh rakyat atau pemerintah. Sebagai contoh dalam konteks demokrasi, bagi memastikan kedaulatan umum dapat dilaksanakan dalam negara maka proses pilihan raya sentiasa menuntut rakyat bertindak secara rasional dalam membuat pilihan semasa mengundi. Ini bagi memastikan pilihan yang dilakukan adalah yang terbaik kepada diri mereka secara khusus dan kepada negara secara umumnya. Oleh itu, proses pilihan raya ini menunjukkan bahawa prinsip utama demokrasi iaitu kedaulatan umum dan hasil daripada pilihan raya tersebut akan terbentuk sebuah kerajaan yang sah menurut perlembagaan dan undang-undang bagi mentadbir negara. Ini dapat menjelaskan bahawa pemerintah atau kerajaan yang dipilih oleh rakyat menerusi pilihan raya akan bertanggungjawab terhadap tindakan dan dasar yang akan dibuat dan dilaksanakan mesti mengambil kira kepentingan dan kebajikan rakyat secara keseluruhannya. Manakala Barrie (1997) pula menegaskan bahawa aspek yang berkaitan dengan prinsip demokrasi meliputi perwakilan, kedaulatan, hak dan kebebasan. Oleh itu, berdasarkan kepada prinsip asas ini maka adalah jelas bahawa sistem politik demokrasi mempunyai prinsip-prinsip utama yang memberi fokus kepada nilai rakyat itu sendiri. Sebagai contoh prinsip yang berkaitan dengan perwakilan dan persaingan adalah juga merupakan prinsip yang mendasari hal ehwal hak asasi setiap rakyat. Ini bermakna prinsip demokrasi adalah selari dengan hak asasi setiap rakyat atau masyarakat dalam sesebuah negara. Sekiranya tanpa amalan atau prinsip demokrasi dalam sesebuah negara, maka ini bermakna hak asasi setiap rakyat adalah tidak wujud dan ini akan menjurus kepada pemerintahan yang tidak demokratik seperti totalitarian atau autorilitarian.

Perbincangan mengenai demokrasi adalah tidak lengkap tanpa aspek pilihan raya dan parti politik. Pilihan raya ialah salah satu bukti hubungan yang jelas antara prinsip demokrasi dan hak asasi rakyat. Dengan adanya pilihan raya, secara langsung prinsip-prinsip demokrasi akan tertunai menerusi perjalanan sesuatu pilihan raya seperti hak mengundi, kesamarataan, kebebasan dan persaingan. Di sini adalah jelas menunjukkan bahawa sesebuah negara yang mengamalkan sistem politik demokrasi akan melibatkan aspek majoriti rakyat dalam pembentukan kerajaan dan pembuatan keputusan. Pilihan raya adalah sebagai platform yang boleh digunakan oleh rakyat atau pengundi untuk membuat pilihan politik bagi menentukan siapa yang akan memerintah negara. Parti politik atau calon yang mendapat undian yang paling banyak atau majoriti akan memenangi pilihan raya dan seterusnya akan memerintah negara. Sehubungan itu, Menurut Roskin (2000) menjelaskan bahawa terdapat keperluan untuk melihat demokrasi dalam sesebuah negara daripada perspektif demokrasi berperwakilan. Oleh itu, aspek perwakilan ialah jawapan kepada realiti demokrasi kini dan dalam hal ini pendekatan pilihan raya ialah kunci kepada demokrasi moden yang ada pada hari ini. Roskin (2000) melihat demokrasi perwakilan sebagai " a democracy in which the people do not rule directly but through elected and accountable representative" (m/s. 72). Kenyataan Roskin ini adalah selari dengan pandangan Ranney (1993) yang menyatakan bahawa "most present-day political theorists believe that direct participation 
by all the millions of citizens in the decision of government in impossible in modern nation" $(\mathrm{m} / \mathrm{s}$. 108). Berdasarkan pandangan Roskin dan Ranney ini maka adalah jelas bahawa demokrasi kini dilihat selari dengan konsep kerajaan berperwakilan dalam proses dan amalan pilihan raya.

Pickles (1970) telah menggariskan salah satu idea utama sistem politik demokrasi ialah sebagai keputusan majoriti dalam pilihan raya. Ini menunjukkan bahawa melalui idea demokrasi, setiap keputusan yang dibuat oleh kerajaan dianggap sebagai keputusan umum yang seharusnya diterima oleh rakyat atau semua lapisan masyarakat. Ini adalah kerana kerajaan merupakan badan tertinggi untuk menentukan dasar sesebuah negara dan rakyat. Demokrasi telah memberi ruang kepada kerajaan atau badan yang memerintah untuk menentukan dasar dan hala tuju negara. Setiap keputusan yang dibuat digambarkan sebagai suatu keputusan oleh rakyat dalam sistem politik demokrasi. Lau dan Redlawsk (2006) telah menjelaskan bahawa kejayaan dalam sistem politik demokrasi adalah apabila sesebuah kerajaan merupakan wakil rakyat yang dipilih melalui proses pilihan raya yang bebas. Ini jelas menunjukkan bahawa rakyat ialah paksi utama dalam sistem demokrasi di sesebuah negara dan rakyat berhak membuat pilihan melalui proses pilihan raya yang bebas untuk memilih wakil mereka dan seterusnya membentuk kerajaan. Sesebuah kerajaan yang berjaya dibentuk hasil daripada proses pilihan raya adalah seharusnya bertindak dan bertanggungjawab kepada rakyat secara keseluruhannya iaitu dengan menjaga kepentingan dan kebajikan rakyat. Ini kerana menurut Lau dan Redlawsk (2006), nilai tanggungjawab dan prestasi kerajaan akan dinilai oleh rakyat semasa pilihan raya yang akan datang. Oleh itu kejayaan sesebuah kerajaan dalam sistem politik demokrasi lebih banyak bergantung kepada nilai tanggungjawab dan menjaga kebajikan rakyat iaitu dengan melakukan tindakan atau dasar yang dapat memberi faedah kepada rakyat secara keseluruhannya. Sekiranya kerajaan gagal bertindak berdasarkan kemahuan majoriti rakyat maka rakyat akan bertindak menolak kerajaan dalam pilihan raya akan datang. Ini kerana keputusan dalam membuat pilihan boleh berubahubah berdasarkan kepada beberapa faktor yang mempengaruhinya.

Secara umumnya dapat difahami hubungan antara sistem demokrasi dan pilihan raya adalah menjurus kepada proses pembentukan kerajaan berdasarkan lunas-lunas perlembagaan dan undang-undang. Sistem demokrasi dan pilihan raya akan mewujudkan pihak yang menyokong dan menentang serta pihak yang menang dan yang kalah. Oleh itu, bagi berlaku adil kepada semua rakyat dalam amalan politik demokrasi maka yang tidak menyokong dan yang kalah seharusnya diberi ruang dan peluang untuk terus berjuang dalam amalan demokrasi. Ini bagi memastikan yang menyokong dan yang menang tidak akan selamanya menang tanpa diberi ruang yang adil di pentas demokrasi dan pilihan raya. Pada masa yang sama juga, pihak yang menang atau pihak yang membentuk kerajaan seharusnya bersifat adil kepada semua rakyat tanpa mengira mereka di pihak menyokong atau di pihak yang menentang. Ini kerana amalan atau prinsip demokrasi tidak membenarkan wujudnya unsur diskriminasi dalam pentadbiran dan pemerintahan selepas memperoleh kuasa menerusi pilihan raya. Dasar dan pendekatan yang diambil mesti menjurus kepada nilai kepentingan rakyat secara keseluruhannya.

\section{Polemik Peralihan Kuasa Secara Luar Biasa}

Dalam sejarah peradaban manusia, peralihan kuasa secara luar biasa sememangnya sering kali terjadi. Seperti yang telah dibincangkan sebelum ini, peralihan kuasa secara luar biasa ini maksudnya berlaku di luar kebiasaan dan tidak mengikut norma dan normal biasa. Dalam perbincangan ini, sangat penting untuk memahami dan mengenal pasti polemik-polemik peralihan yang berlaku secara luar biasa. Teori peralihan kuasa dikenal pasti sebagai suatu pendekatan yang berstruktur dan dinamik dalam dunia politik. Peralihan kuasa yang berlaku membentuk satu paradigma bahawa sebenarnya tidak banyak bezanya antara politik domestik dan politik antarabangsa kecuali perbezaan tersebut berlaku bergantung kepada tahap komitmen terhadap status quo di bawah perubahan struktur kuasa. Pasca Perang Dingin menyaksikan perubahan pendekatan dalam peralihan kuasa. Peralihan kuasa sebelum ini dikaitkan dengan peperangan dan kaitannya lebih ketara dalam konteks kuasa dalam hubungan antarabangsa. Walau bagaimanapun, kemunculan kembali konflik kuasa-kuasa besar dan peralihan kuasa yang berlaku di beberapa buah negara khususnya di negara-negara timur tengah yang bergolak 
menyaksikan juga kebangkitan teoretis yang kembali memfokuskan kepada peranan kuasa (Rauch, 2018).

Di Syria dan Ukraine misalnya, Amerika Syarikat dan Rusia masing-masing menyokong pihak yang mampu memberikan manfaat kepada mereka dalam mengekalkan status kuasa besar dunia dan sentimental yang berlaku semasa Perang Dingin sedikit sebanyak muncul kembali. Dalam kajian politik antarabangsa, teori peralihan kuasa merupakan pendekatan yang sering kali diguna pakai dalam menganalisis isu-isu dan polemik-polemik peralihan kuasa di dunia. Teori peralihan kuasa ini diperkenalkan oleh Kugler dan Organski (1958) dan telah dikembangkan dengan lebih lanjut oleh sarjana-sarjana yang lain. Sebagaimana yang ditunjukkan dalam Rajah 1, teori ini menggambarkan politik antarabangsa sebagai sebuah hierarki dengan teori peralihan kuasa menggambarkan politik antarabangsa sebagai sebuah hierarki dengan negara-negara yang dominan atau pemimpin sistem terletak pada kedudukan tertinggi, yang menikmati sumber kuasa yang terbesar dari segi populasi, produktiviti, dan keupayaan politik yang bermaksud koheren dan kestabilan. Di tangga kedua, terletaknya kuasa dunia iaitu sekumpulan pesaing yang berpotensi menjadi negara dominan dan yang berkongsi tugas menjalankan sistem dan mengawal peruntukan sumber kuasa. Di tangga ketiga, terdapatnya kuasa pertengahan yang sangat signifikan di rantaunya yang serupa dengan negara dominan, tetapi tidak dapat mencabar negara-negara dominan atau struktur sistem, dan di tangga terbawah, wujudnya kuasa kecil iaitu kategori yang merangkumi semua negara lain dalam sistem antarabangsa (Kim, 1997; Tammen, 2000).

\section{Rajah 1: Hierarki kuasa negara dalam Teori Peralihan Kuasa}

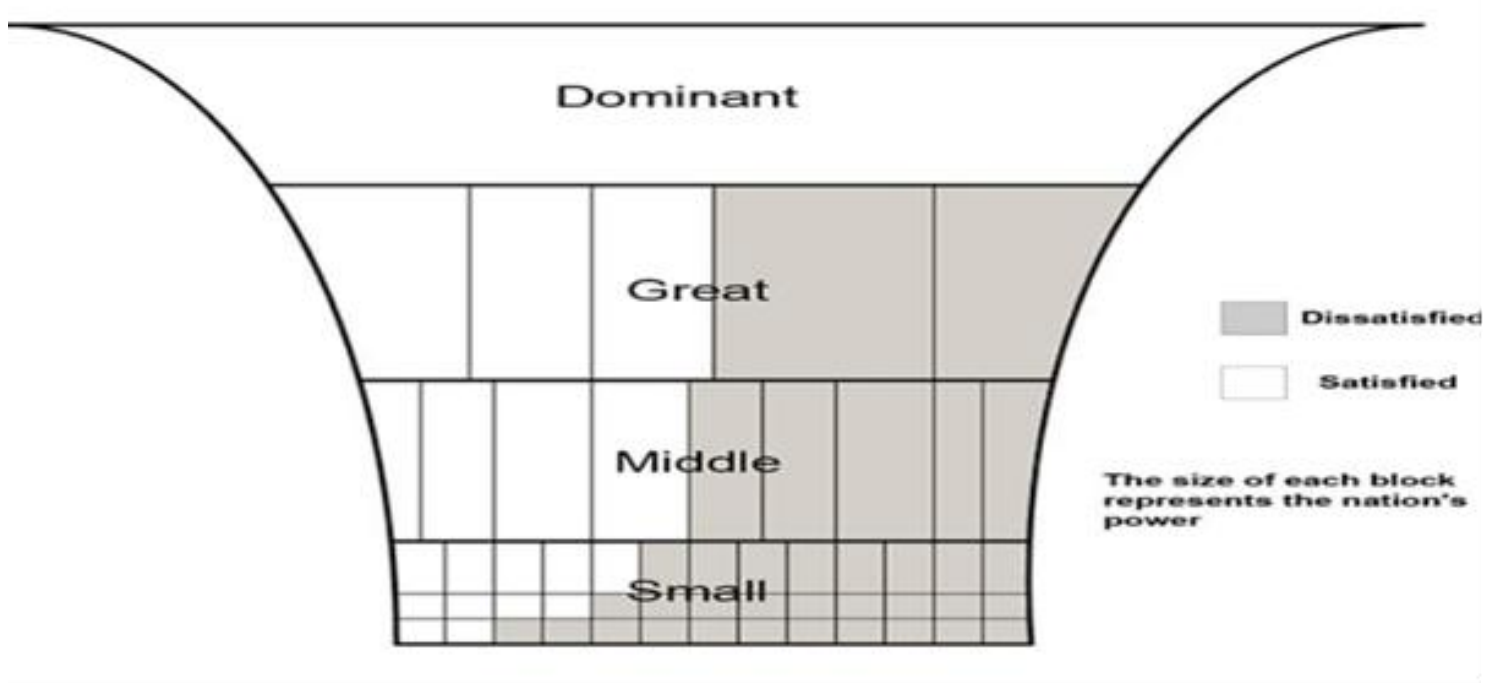

Sumber: Kugler dan Organski (1958)

Peperangan juga berkemungkinan berlaku dalam tempoh yang lama dan dalam skala yang besar jika munculnya pencabar kepada kuasa dominan memiliki kesetaraan dan tahap sistem ketenteraannya yang lebih kurang dengan negara yang dominan dan tidak berpuas hati dengan sistem yang sedia ada. Begitu juga, pakatan merupakan kaedah paling selamat dan stabil apabila pihak-pihak yang bersekutu berpuas hati dengan struktur sistem. Terdapat lebih banyak lagi nuansa pada teori ini seperti, sumbersumber peralihan kuasa berbeza-beza dari sudut ketidaktentuannya, perubahan populasi menjadi yang paling kurang bagi ketidaktentuannya dan keupayaan politik yang ditakrifkan sebagai keupayaan kerajaan untuk mengawal sumber-sumber dalaman negara adalah yang paling tidak menentu (Kugler \& Lemke, 2000; Rauch, 2018).

Dalam konteks Malaysia, polemik-polemik yang berlaku secara global dan domestik perlu diperhalusi lebih-lebih lagi di negara-negara tetangga bagi memastikan isu-isu tersebut difahami dan paling penting, bagi mengelakkan polemik-polemik tersebut difahami dengan konteks dan konsep yang tidak bertepatan dengan senario dan situasi yang berlaku di negara kita. Dalam konteks Malaysia, setiap peralihan kuasa politik khususnya melibatkan peralihan kuasa seseorang Perdana Menteri yang 
berlaku sejak pasca merdeka dan pembentukan Malaysia dilihat masih berlaku dalam lunas dan konteks demokrasi berparlimen dan raja berperlembagaan. Dalam konteks artikel ini, jika disoroti beberapa buah negara tetangga, terdapat beberapa peristiwa penting yang berlaku melibatkan peralihan kuasa secara luar biasa dan berbeza dengan yang berlaku di Malaysia (Caballero-Anthony, 2005; Mizuno \& Phongpaichit, 2009).

Terdapat beberapa peristiwa penting di Thailand, Indonesia dan Myanmar yang dapat dikenal pasti dalam konteks peralihan kuasa secara luar biasa. Di Thailand misalnya, sejak kudeta (pemerintahan junta tentera) pada tahun 2014, pilihan raya umum pertama diadakan pada bulan Mac 2019. Parti Phalang Pracharat yang baru sahaja ditubuhkan pada tahun 2018 telah memenangi pilihan raya umum tersebut dan calon perdana menterinya, Prayut Chan-o-cha, (sebelum ini seorang Panglima angkatan tentera Thailand) kekal dengan jawatan tersebut sejak peristiwa kudeta Thailand pada Mei 2014 yang merekodkan perdana menteri sebelum ini Yingluck Shinawatra digulingkan. Kudeta oleh junta tentera di Thailand bukanlah perkara luar biasa dan sememangnya pernah berlaku, namun kali ini, tentera Thailand di bawah pemerintahan Prayut yang mengambil alih tampuk pemerintahan negara enggan menyerahkan kuasa pemerintahan kepada parti demokrat seperti amalan biasa sebelum ini. Ketidaktentuan politik ini membawa kepada perpecahan antara parti demokrat dengan junta tentera (Mizuno \& Phongpaichit, 2009; Wong, 2020).

Walaupun pemerintahan Prayut dikritik kerana disifatkan sebagai "autoritarian”, pemerintahan Prayut dalam tempoh lima tahun yang berlalu telah menyaksikan keamanan dan kestabilan di Thailand. Selepas beberapa tempoh masa ekonomi Thailand merudum, ia telah kembali pulih dan stabil selepas empat tahun berturut-turut. Walaupun terdapat kebimbangan mengenai penglibatan junta tentera secara terus menerus dalam politik Thailand yang akan menyebabkan ia menjadi semakin autokratik, tetapi mengambil kira senario dan suasana semasa Thailand yang telah lama lumpuh akibat pelaksanaan sistem demokrasi yang melampau, sumbangan positif junta tentera sebagai ejen penstabil politik, sosial dan ekonomi Thailand tidak dapat dinafikan (Mizuno \& Phongpaichit, 2009; Wong, 2020).

Di Indonesia, antara peristiwa peralihan kuasa yang paling diingati yang sangat berkait rapat dengan Malaysia ialah peralihan kuasa daripada Sukarno kepada Suharto. Tercetusnya peristiwa Gerakan September 30 (GESTAPU) pada 1 Oktober 1965 di Indonesia menjadi titik permulaan kejatuhan Sukarno sebagai pemimpin ulung Indonesia. Berikutan daripada peristiwa tersebut juga telah meredakan dasar konfrontasi Indonesia terhadap Malaysia. Perubahan kepimpinan tersebut memperlihatkan usaha perdamaian dan penamatan konfrontasi dilaksanakan secara intensif terutamanya selepas pembentukan kabinet baru pada 4 April 1966 dengan pelantikan Adam Malik sebagai Menteri Luar Indonesia bagi membolehkan usaha penamatan konflik antara kedua-dua negara ini dapat diselesaikan (Abd Razak, 2001; Caballero-Anthony, 2005 \& Parameswaran, 2020).

Dapat disimpulkan di sini bahawa berlakunya peralihan kuasa dalam kalangan negara-negara tetangga Malaysia sedikit sebanyak memberikan kesan yang luar biasa walaupun peralihan kuasa tersebut berlaku dalam keadaan yang biasa. Polemik-polemik yang berlaku juga menunjukkan bahawa setiap negara termasuklah Malaysia seharusnya mengambil langkah yang strategik dan sistematik bagi memastikan isu-isu yang berlaku di persekitarannya tidak memberikan implikasi negatif terutamanya daripada aspek kedaulatan dan keselamatan negara.

\section{Melestarikan Demokrasi Berparlimen}

Sebagaimana yang diketengahkan sebelum ini dan menurut Mohd Azmir dan Afi (2019), Malaysia telah memilih sistem demokrasi berparlimen yang unik serta telah diwarisi sejak zaman berzaman semenjak sebelum Malaysia terbentuk pada 16 September 1963 iaitu selepas Tanah Melayu mencapai kemerdekaan pada 31 Ogos 1957. Dalam pada itu, sebagai sebuah negara yang mengamalkan sistem demokrasi berparlimen, Malaysia telah berjaya mengharungi 14 pilihan raya umum bermula pada tahun 1955. Pilihan raya di negara ini merupakan kemuncak sistem demokrasi berperlembagaan yang turut menjadi pentas perang bagi kesemua parti yang bertanding kerana ia merupakan medium utama 
di mana setiap rakyat yang berdaftar sebagai pengundi berhak memilih tampuk kepimpinan negara sama ada di peringkat persekutuan ataupun di peringkat Negeri (Mohd Azmir \& Afi, 2019). Namun, sejak berakhirnya PRU14, sistem demokrasi berperlembagaan boleh digambarkan sebagai suatu sistem yang mengalami cabaran baru dan wajar ditangani bagi memastikan kelestariannya dapat dijamin. Cabaran ketara yang dapat dikenal pasti ialah munculnya usaha dari pelbagai pihak untuk memastikan penggantian pucuk pimpinan negara iaitu Perdana Menteri dilakukan seberepa segera yang mungkin. Hal ini sudah semestinya merupakan suatu fenomena baru yang boleh mengagalkan pelestarian sistem demokrasi yang telah kita amalkan sejak sekian lama. Sebagaimana menurut responden berumur 52 tahun yang ditemu duga bagi tujuan kajian berkaitan kertas kerja ini, polemik peralihan kuasa yang semakin digembar-gemburkan di negara ini boleh mencacatkan sistem demokrasi berparlimen di Malaysia. Beliau menegaskan bahawa "keinginan pelbagai pihak untuk merealisasikan peralihan kuasa melalui kaedah yang tidak normal iaitu bukan melalui proses pilihan raya sudah semestinya boleh menjadi asas kepada keruntuhan demokrasi berparlimen di negara ini". Di samping kenyataan tersebut, responden belia berumur 25 tahun juga turut sependapat dengan beliau apabila responden ini berkata, "kita berharap semua ahli politik berlapang dada dan tidak melakukan sesuatu yang boleh menyebabkan sistem demokrasi berparlimen di negara tidak terjejas".

Berdasarkan kenyataan oleh dua orang responden tadi maka sudah jelaslah bahawa memang wujud kebimbangan dalam kalangan rakyat di negara ini tentang kemungkinan sistem demokrasi berparlimen tidak mampu dilestarikan berikutan polemik peralihan kuasa bagi jawatan Perdana Menteri.

Isu utama yang berlegar di negara ini berkaitan peralihan kuasa bermula apabila dikhabarkan oleh pelbagai pihak bahawa wujudnya persetujuan di antara Tun Dr Mahathir Mohamed dan Dato Seri Anwar Ibrahim sebelum PRU-14 untuk memastikan hal ini berlaku. Sebagaimana yang digembargemburkan oleh media masa, Tun Dr Mahathir dipilih sebagai Perdana Menteri sekiranya PH memenangi PRU-14 dan seterusnya selepas beberapa tempoh masa tertentu Tun Dr Mahathir akan meletak jawatan bagi memberi laluan kepada Dato Seri Anwar Ibrahim untuk menjadi Perdana Menteri. Disebabkan itu, Presiden Parti Keadilan Rakyat (PKR), Dato Seri Anwar Ibrahim dan pengikutnya telah mula menuntut janji tersebut selepas Tun Dr Mahathir berada di singgahsana selama lebih dari setahun. Sekalipun ramai pihak berpendapat bahawa Presiden PKR yang menjadi watak utama dalam usaha menuntut peralihan itu wajar supaya didahulukan kepentingan mentadbir negara daripada perbahasan peralihan kuasa, usaha masih lagi terus dilakukan oleh pelbagai pihak. Malah ada juga pihak lain dari parti United Malay National Organization (UMNO) iaitu Tengku Razaleigh Hamzah yang menyifatkan desakan pelbagai pihak supaya disegerakan peralihan kuasa Perdana Menteri berdasarkan perjanjian antara parti komponen Pakatan Harapan (PH) tidak boleh dipakai. Kenyataan seumpama ini sememangnya wajar berikutan hakikat bahawa peralihan kuasa mengikut apa yang dijanjikan itu sebenarnya di luar daripada ketetapan peruntukan dalam Perlembagaan Persekutuan. Sedangkan Tun Dr Mahathir Mohamad dilantik sebagai Perdana Menteri mengikut Perlembagaan Persekutuan dan dipersetujui serta mendapat sokongan majoriti dalam Parlimen. Tambahan pula, Perlembagaan Malaysia dengan jelas menyebut bahawa, peralihan kuasa Perdana Menteri hanya boleh berlaku sekiranya Perdana Menteri berhenti, mati atau usul tidak percaya di Dewan Rakyat. Sebaliknya jika keadaan yang disebutkan tidak berlaku maka Tun Dr Mahathir wajar untuk kekal sebagai Perdana Menteri sehingga habis penggal.

Di sebalik hakikat ini dan ketika jelas bahawa kerajaan Pakatan Harapan (PH) dan sekutunya dianggap sebagai terumbang-ambing dan lemah pelbagai pihak cuba memecahkan kebuntuan terhadap isu peralihan kuasa di antara Dr Mahathir Mohamad dan Anwar Ibrahim. Sebagaimana menurut MalaysiaKini (14 Jun 2020), di tengah pergeseran itu, Mahathir telah menawarkan Anwar jawatan timbalan perdana menteri, sementara beliau mengambil alih jawatan perdana menteri selama enam bulan sebelum melakukan peralihan kuasa. Namun cadangan tersebut sukar dipersetujui oleh Anwar dan para pemimpin PKR. Malahan turut dilaporkan oleh MalaysiaKini (14 Jun 2020) bahawa para pemimpin PKR makin tidak meletakkan keyakinan bahawa Mahathir akan menepati janji yang telah dibuat berkaitan peralihan kuasa. Ketidakyakinan terhadap Mahathir ini memberi gambaran jelas bahawa para pemimpin PKR hanya bersedia memberikan sokongan untuk mengambil alih semula kerajaan sekiranya Anwar menjadi perdana menteri. Asas utama kepada hal ini ialah berikutan terdapatnya bukti yang diperoleh oleh sebilangan pemimpin PKR bahawa dalam salah satu mesyuarat 
dalaman parti Bersatu, Mahathir dikatakan telah melafazkan kesediaan beliau untuk menepati janjinya untuk mengundurkan diri sebagai perdana Menteri. Namun demikian, Mahathir juga dikesan sebagai masih lagi tidak bersedia mengumpulkan sokongan anggota parlimen Bersatu terhadap Anwar. Dalam rakaman audio yang bocor itu, beliau bahkan kedengaran mencadangkan agar beliau kembali menjadi perdana menteri setelah mengundurkan diri sekiranya Anwar tidak mendapat sokongan majoriti di Dewan Rakyat dan meminta para pemimpin Bersatu tidak menekannya menyingkirkan PH sehingga tiba waktunya.

Sejajar dengan itu, para pemimpin Bersatu dan disokong oleh sebilangan pemimpin PKR, telah mengorak langkah yang lebih agresif dengan merencanakan 'Langkah Sheraton' untuk membentuk kerajaan baru dengan Barisan Nasional (BN), Parti Islam Se-Malaysia (PAS), Gabungan Politik Sarawak (GPS), Parti Bersatu Sabah (PBS) dan STAR di bawah Perikatan Nasional. Bermula daripada usaha tersebut maka akhirnya kerajaan PH tumbang dan seterusnya diganti oleh kerajaan baru yang dikenali sebagai kerajaan kerajaan Pakatan Nasional (PN). Sejak itu, isu peralihan kuasa perdana Menteri tidak pernah terhenti. Malahan terdapat usaha untuk menamakan pemimpin lain untuk diangkat sebagai perdana Menteri mahupun usaha untuk menjatuhkan kerajaan PN.

Kesan daripada perkembangan ini maka landskap politik negara tidak lagi boleh dianggap sebagai stabil kerana kerajaan yang ada dianggap sebagai boleh tumbang pada bila-bila masa. Malahan ada pihak yang beranggapan bahawa segala usaha yang sewajarnya dilakukan oleh para pemimpin untuk mengangkat martabat negara ke suatu tahap yang lebih tinggi semakin terbantut. Ini berlaku berikutan tumpuan lebih diberikan di kalangan pemimpin kepada usaha mengekalkan kuasa politik masingmasing berbanding memastikan kesejahteraan rakyat terjamin. Atas sebab ini, perlu ditegaskan bahawa polemik peralihan kuasa pasca PRU-14 merupakan suatu yang tidak normal, membimbangkan, mendatangkan lebih keburukan daripada kebaikan serta wajar dihentikan.

Kesan akhir kepada keadaan sebuah negara yang menumpukan lebih perhatian kepada peralihan kuasa secara tidak normal mengikut lunas-lunas demokrasi ini ialah keruntuhan sistem demokrasi berparlimen. Maka sudah semestinya suatu usaha wajar dilakukan untuk memastikan hal ini tidak berlaku. Antara kaedah yang boleh diguna pakai adalah dengan menyeru Duli Yang Maha Mulia Yang Dipertuan Agung memainkan peranan yang lebih tegas dalam memastikan semua ahli politik di negara ini berlapang dada dan memberi tumpuan sepenuhnya kepada usaha mensejahterakan kehidupan rakyat di negara ini. Diakui juga bahawa usaha meningkatkan kesedaran di kalangan rakyat tentang pentingnya memilih pemimpin yang tidak mementingkan diri sahaja tetapi lebih mementingkan kebajikan rakyat dan negara secara amnya. Ini boleh dilakukan melalui proses demokrasi dengan memastikan hanya pemimpin yang demikian dipilih dan diangkat sebagai peneraju kepimpinan negara. Tanpa berbuat demikian, dibimbangi suatu hari nanti negara ini akan berdepan dengan kemelut yang lebih besar dan sukar diatasi.

\section{Kesimpulan}

Malaysia sebagai sebuah negara yang mengamalkan sistem demokrasi berparlimen mempunyai keunikannya yang tersendiri. Hal ini memungkinkan keadaannya berbeza dengan negara-negara lain di Asia Tenggara. Warisan kolonial British disulami dengan tradisi pemerintahan lokal menjadikannya menarik untuk dibincangkan dan diperdebatkan apabila kini mula dicabar dengan isu peralihan kuasa. Norma baharu dalam kehidupan sepanjang pandemik Covid-19 rupanya turut memberi kesan kepada suasana politik negara. Norma baharu dalam politik Malaysia dapat dilihat apabila perubahan kuasa berlaku tanpa dijangka dan diramalkan. PH tumbang dalam tempoh yang begitu singkat masa pemerintahannya yang kemudian kuasa diambil alih oleh PN. Tempoh masa yang sesingkat ini dianggap luar biasa yang tidak pernah berlaku dalam sejarah negara sejak kemerdekaan. Sekali lagi isu kepimpinan jawatan Perdana Menteri menjadi faktor dominan dalam pergolakan tersebut. Isu ini mengheret kepada beberapa persoalan seperti perlembagaan Malaysia, Majlis Raja-raja dan institusi parlimen, serta amalannya dalam sistem demokrasi tersebut. Dalam kekalutan tersebut, YDPA dan institusinya mengadaptasikan perlembagaan dalam meleraikan isu itu dengan pelantikan Tan Sri Muyiddin Yassin sebagai Perdana Menteri Malaysia yang kelapan. 
Polemik peralihan kuasa ini perlu ditangani secara hikmah kerana natijahnya akan memberikan kesan kepada rakyat dan negara. Negara berada dalam keadaan yang tidak stabil daripada segi pemerintahan dan pentadbiran, serta menjejaskan kematangan sistem demokrasi berparlimen Malaysia. Hal ini sudah tentu akan menjejaskan kestabilan ekonomi dan membimbangkan pelabur asing. Rakyat juga berada dalam keadaan kegelisahan dan 'muak' dengan isu politiking yang melampau tiada kesudahannya. Apa pun jelas rakyat Malaysia telah menampakkan elemen kematangan berpolitik, Malaysia masih aman sejahtera dalam pada masa yang sama mula menampakkan kejayaan menangani isu pandemik Covid19. Namun begitu, keadaan ini tidak seiring dengan kematangan para pemimpinnya dalam berpolitik sehingga menjejaskan sistem demokrasi berparlimen. Hal inilah yang dianggap luar biasa yang suatu hari nanti menjadi perencah kepada corak dan warna sejarah politik Malaysia.

\section{Penghargaan:}

Artikel ini merupakan sebahagian daripada kajian penyelidikan penulis mengenai 'Integriti Pilihan Raya dalam Pelaksanaan Demokrasi di Sabah, Malaysia' dari November 2019 hingga kini (akan berakhir pada Disember 2020). Penulis ingin mengucapkan setinggi-tinggi penghargaan kepada Pusat penataran Ilmu dan Bahasa, Universiti Malaysia Sabah atas pembiayaan penyelidikan ini.

\section{Rujukan}

Abd Razak, M.R. (2001). Gestapu dan penyelesaian konfrontasi Malaysia - Indonesia. JEBAT: Malaysian Journal of History, Politics and Strategic Studies, 28, 75-106.

Ahmad Tarmizi Abdul Rahman, Romzi Ationg \& Nurul Ain Zulhaimi (2017). A paradigm shift in understanding mixed method research: A Malaysian perspective. Journal of Advanced Research in Social and Behavioural Sciences, 9(1), 46-56.

Caballero-Anthony, M. (2005). Political transitions in Southeast Asia. Southeast Asian Affairs, 24-44.

Chan, Tsu Chong. (2018). Democratic Breakthrough in Malaysia - Political Opportunities and the Role of Bersih. Journal of Current Southeast Asian Affairs, 37, 3.

Kim, W. (1997). Power transition and strategic stability in East Asia. Asian Perspective, 21(1), 153170.

Kugler, J. \& Lemke, D. (2000). The power transition research program: Assessing theoretical and empirical advances (m/s. 129-163). Dlm M.I., Midlarsky. (ed.). Handbook of War Studies II. Michigan: University of Michigan Press.

Kugler, J. \& Organski, K. (1958). The Power Transition: A Retrospective and Prospective Evaluation (m/s. 172-194). Dlm. M.I., Mildrasky. (ed.). Handbook of War Studies. Michigan: The University of Michigan Press.

MalaysiaKini (14 Jun 2020). Rancangan peralihan kuasa goyah akibat kebuntuan antara Dr M, Anwar. Dalam talian sesawang: https://www.malaysiakini.com/news/530226

Mizuno, K. \& Phongpaichit, P. (2009). Populism in Asia. Singapore: NUS Press and Kyoto University Press.

Mohd Azmir Mohd Nizahi \& Afi Roshezry Abu Bakar. (2019), Demokrasi Pilihanraya dan Cakna Perlembagaan: Tajuk Yang Sama, Topik Yang Berbeza. I_STET, 39-43.

Mohd Azri Ibrahim, Romzi Ationg, Mohd Sohaimi Esa \& Madiyem Layapan (2020). Analisis pola pengundian dan senario politik semasa di Malaysia era pasca Pilihan Raya Umum (PRU) ke-14 berdasarkan pilihanraya kecil P168 Sandakan, Sabah. Malaysia Journal of Social Sciences and Humanities, 5(5), 60-71.

Moniruzzaman, M.D. \& Farzana, K.F. (2018). Malaysia' 14th general election: End of an epoch, and beginning of a new? Intellectual Discourse, 26, 1.

Muhamad Nadzri Mohamed Noor \& Nidzam Sulaiman. (2018). Mitos dan Realiti Dalam Situasi Hubungan Sosial di Awal Era Transisi Malaysia Baharu: Satu Perbahasan. Dlm. Kartini Aboo Khalid, Noorrulhawa Abu Bakar, Phoon Li \& Roovasini (eds.). Buku Prosiding International Colloquium on Integration Platform: Binding Differences and Diversity: Akal Budi Alam Melayu (ICIP2018). Bangi: Institut Kajian Etnik, UKM. 
DOI: https://doi.org/10.47405/mjssh.v5i11.552

Muhammad Nadzri Mohamed Noor. (2018). The 14th General Election, the fall of Barisan Nasional, and political development in Malaysia, 1957-2018. Southeast Asian Affairs 37(3), 139-171.

Parameswaran, P. (2020). What does Malaysia's troubled transition mean for democracy in Southeast Asia. The Diplomat. Dalam Talian Sesawang: https://thediplomat.com/2020/05/what-doesmalaysias-troubled-transition-mean-for-democracy-in-southeast-asia/

Rauch, C. (2018). Realism and power transition theory: Different branches of the power tree. Realism in Practice, 19(1), 1-11.

Romzi Ationg (2017). Federal Political Elites and the Expansion of Ethnic Politics to the Periphery State of Sabah in Malaysia. PhD Thesis, Australian National University, Canberra, Australia.

Shad Saleem Faruqi. (2020). Appointment of a Prime Minister. Tun Hussein Onn Chair. Institute of Strategic and International Studies (ISIS, Malaysia). Dalam Talian Sesawang: https://law.um. edu.my/Research-

Consti/Presentations\%20and\%20Publications/APPOINTMENT\%20OF\%20PM\%20$\% 20 \mathrm{March} \% 202020$.pdf

Tammen, R.L. (2000). Power transitions: Strategies for the 21 st century. Chatham House Publishers.

Welsh, B. (2018). 'Saviour' Politics and Malaysia's 2018 Electoral Democratic Breakthrough: Rethinking Explanatory Narratives and Implications. Journal of Current Southeast Asian Affairs Special Issue: The 2018 Malaysian General Elections, 37, 3.

Wong, A.R. (2020). Dunia tanpa tembok III. Kuala Lumpur: Patriots Publishing Sdn. Bhd. 